\title{
REMODELLING THE MODEL
}

\author{
Thomas Wilson* \\ University of Borås
}

\begin{abstract}
This very short note was originally prepared as a "Viewpoint" for the virtual ISIC conference organized from Pretoria, South Africa in September/October 2020. The idea of the viewpoints was to allow some well-known figures from the world of information behaviour, to present points of view or ideas on current developments, without the necessity for the formal submission and presentation of papers. Consequently, this short note lacks the structure of a formal paper and is simply some personal notes on my current thinking about information behaviour. Keywords: information processing; models; information behaviour.
\end{abstract}

Título: REMODELANDO EL MODELO.

Resumen: Esta nota se preparó originalmente como "Punto de vista" para la conferencia virtual ISIC 2020 ('Information Seeking in Context') organizada este año por la Universidad de Pretoria (Sudáfrica) en septiembre/octubre de 2020. Este formato permitía que algunas figuras bien conocidas del mundo del comportamiento informacional presentaran puntos de vista o ideas sobre los acontecimientos actuales, sin necesidad de presentar oficialmente las ponencias. Por consiguiente, esta breve nota carece de la estructura de un documento formal recogiendo notas personales sobre la necesidad de replantear varias cuestiones alrededor de nuestra propuesta original del modelo de comportamiento informacional original del año 1999, por medio de un proceso de rediseño y actualización del mismo.

Palabras clave: procesamiento de la información; modelos; comportamiento informacional.

Copyright: (C) 2020 Servicio de Publicaciones de la Universidad de Murcia (Spain). Este es un artículo de acceso abierto distribuido bajo los términos de la licencia Creative Commons Reconocimiento 4.0 Internacional (CC BY $4.0)$.

For the past couple of years I've been very slowly writing a short book about information behaviour, centred on the models I've produced over the years. I thought that, for this presentation, it might be interesting to review what I've been doing.

The various models I have published, over the years, are diagrammatic, rather than mathematical. This is rather common in the social sciences because it is often difficult to find a measure for a variable, other than, for example, using scales in questionnaires. It would be possible, of course, to create a mathematical model, such as:

$$
\mathrm{P}_{\mathrm{S}}=(\mathrm{N}(\mathrm{S})+\mathrm{R}+\mathrm{Se}) / 100
$$

Figure 1. A pseudo-mathematical model.

which says, "The probability of a person seeking information equals the strength of the information need, multiplied by the strength of the experienced stress, plus the level of resource ability, plus the level of self-efficacy of the person". Which is probably quite a plausible theoretical hypothesis, but for which there are no standard measures for the variables. We would have to construct scales for each variable and seek responses from people, check the validity and reliability of the scales, and perhaps re-use them on a different population for further validation.

Diagrammatic, theoretical models are intended to show the relationships among variables that affect some phenomenon and there is a certain confusion about what they are trying to do. Generally, such models define categories of variables, not every variable within that category. Consequently, if a model includes the category demographic characteristics, we do not expect the model to list every such characteristic, but simply to give examples that may have been studied in the literature. If someone chooses to explore a new characteristic, that simply provides evidence for the value of the class of characteristics. Nothing is missing, because the category, by definition, includes everything that has been, is now, or will be, in the future, a demographic characteristic.

The model shown below is probably the one best known to people:

*wilsontd@gmail.com

Recibido: 06-10-2020; aceptado: 15-10-2020.

WILSON, T. Remodelando el modelo. Anales de Documentación, 2020, vol. 23, $\mathrm{n}^{\mathrm{o}}$ 2. Disponible en: http://dx.doi.org/10.6018/analesdoc.449171. 


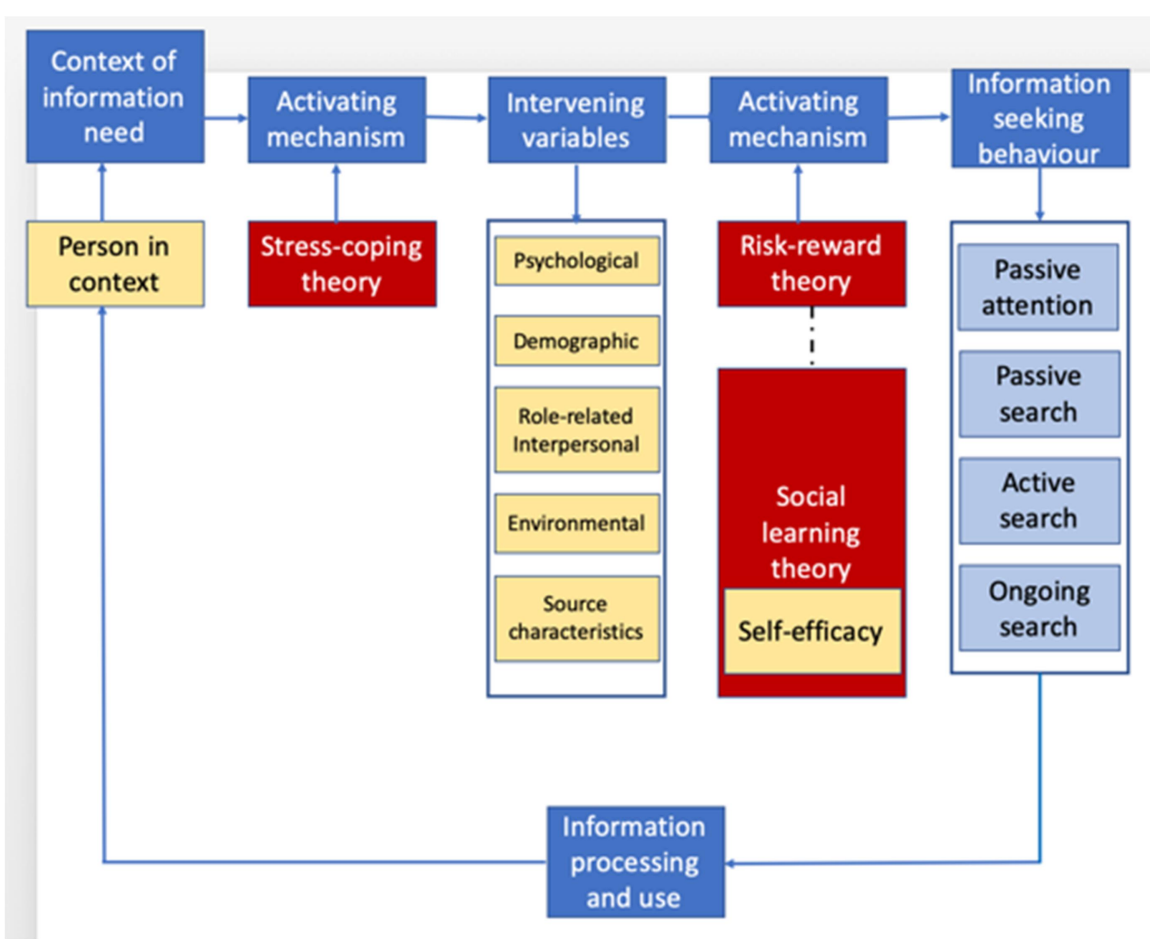

Figure 2. A model of information behaviour (Wilson, 1999).

and it seems to have been useful in helping researchers to evolve their own research questions.

However, I had been unhappy with the phrase information seeking behaviour from the beginning because it suggests an intended behaviour, whereas, as we know, we may come across information while doing other things, which I had called passive behaviour. I think now that if we talk about information discovery rather than information seeking behaviour, that term covers all of the ways in which we might discover information, through intentional seeking and accidental discovery, serendipitously.

The basic model can be represented in this form:

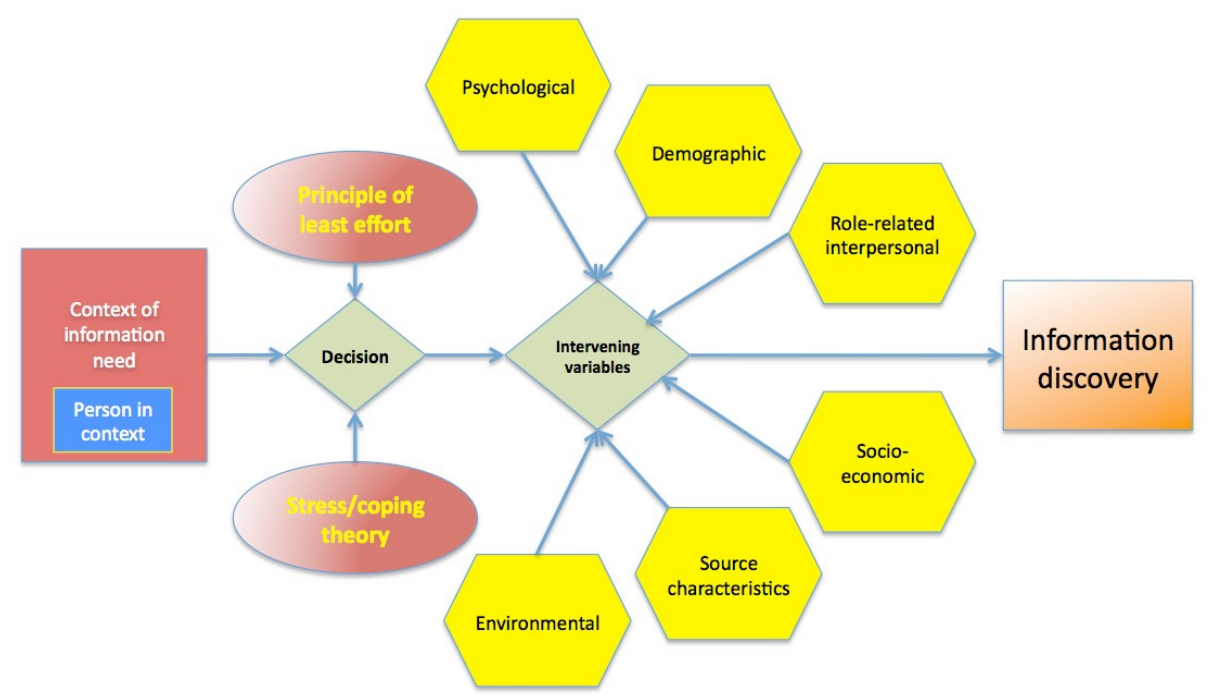

Figure 3. The decision point. 
Note that only one decision is indicated in the diagram, for simplicity. However, a person may decide not to seek information, on the grounds, for example, that the effort required might be more that he or she wishes to invest, or the person may decide to avoid information; he or she may be in the health information jargon, a blunter rather than a monitor. If we wished to include these decisions in the model then we need to expand it to hypothesise the factors that enter into the decision. The first elements in the diagram would then look like this:

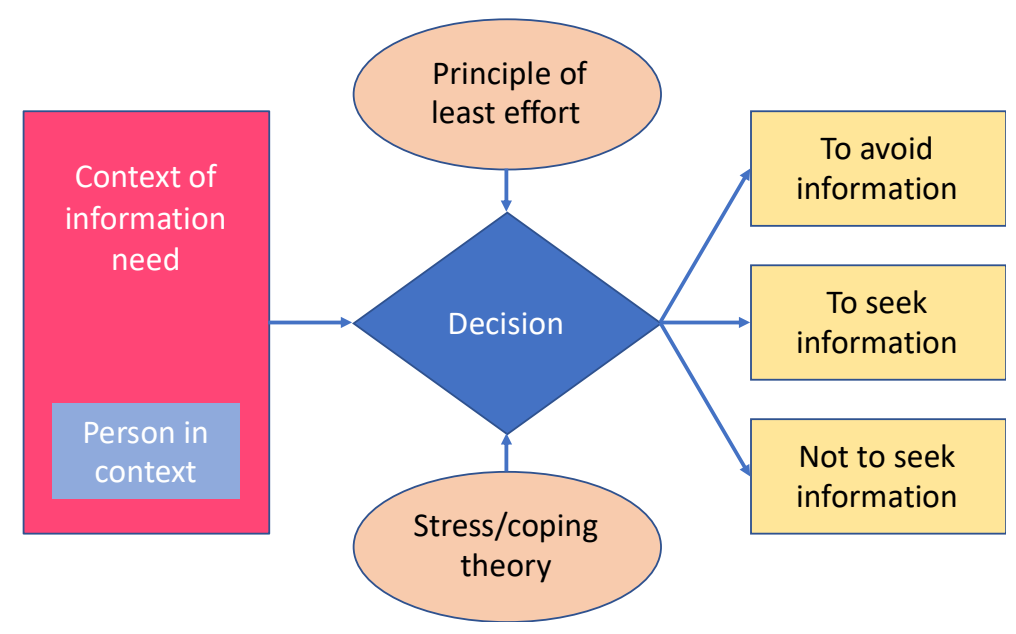

Figure 4. Multiple decisions.

And, of course, each of those yellow boxes would need a similar set of intervening variables that influence that decision and the model would become very difficult to get on to a single page. It would be better to use the general framework of Figure 2 and construct a model for each decision.

The model I presented in 1999 (it had been developed as a result of a research project reported on in 1996) I used the terms passive attention, passive search, active search and ongoing search and I have reviewed these in the light of adopting the term information discovery. I now propose that information may be discovered intentionally or accidentally, and that accidental discovery may come about through passive attention (as in the case of learning something about a product from a television advertisement) or coincidentally - that is, while engaged in some other activity, this coincidental discovery is called by other names - serendipitous discovery (see, e.g., Agarwal, 2015) and information encountering (Erdelez, 2000).

I propose that intentional discovery occurs through two activities: a considered search, that is, one deliberately planned, with the aim of discovery of information relevant to a current task, problem or issue, and keeping informed, which we do simply to keep up to date with an area in which we have an abiding interest.

My new typology of information discovery (one element of the overall model) now looks like this:

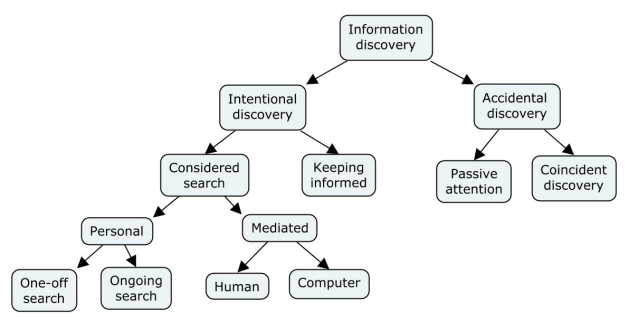

Figure 5. A typology of information discovery.

Bear in mind what I said earlier - the boxes are variables and actions in a theoretical framework, they do not describe the processes undertaken by a person. You can think of this typology as replacing the boxes underneath information seeking behaviour in the Figure 2.

Consequently, everything can be expanded, e.g., by changing the spacing I could have shown that "Keeping informed" might include "personal monitoring" and "computer alerts", and, in some situations, such as teamwork, one 
might add, "peer information sharing" as a way of keeping informed. In a research project these could become three variables in a study of keeping informed and respondents could be asked about the extent to which they are kept informed by these different means.

Similarly, we can develop passive attention and coincident discovery, by setting out the circumstances in which these modes of discovery may occur. For example, passive attention implies that we are attending to some mode of communication and we might list at least some of the modes in which information discovery might take place. I have cited watching TV and, without looking for it, learn something of interest to a current project or task. The same could apply to listening to the radio or a podcast, and possibly more.

Coincident discovery occurs when we are actively engaged and come across information of relevance to some interest or task. Opinion seems to be divided somewhat on how discovery of this kind may come about, but an example may be when we are reading a paper on a topic of general interest and discover a reference to work that is of greater relevance for a project we are currently engaged in.

When we get deeper into these activities, however, we begin to move from developing a theoretical model to developing a process model, because once we have said, A one-off search is one mode of information discovery, we then ask, How is this done? And we need a process model to answer that question.

We can now produce an remodelled version of the 1995 model, as in Figure 6:

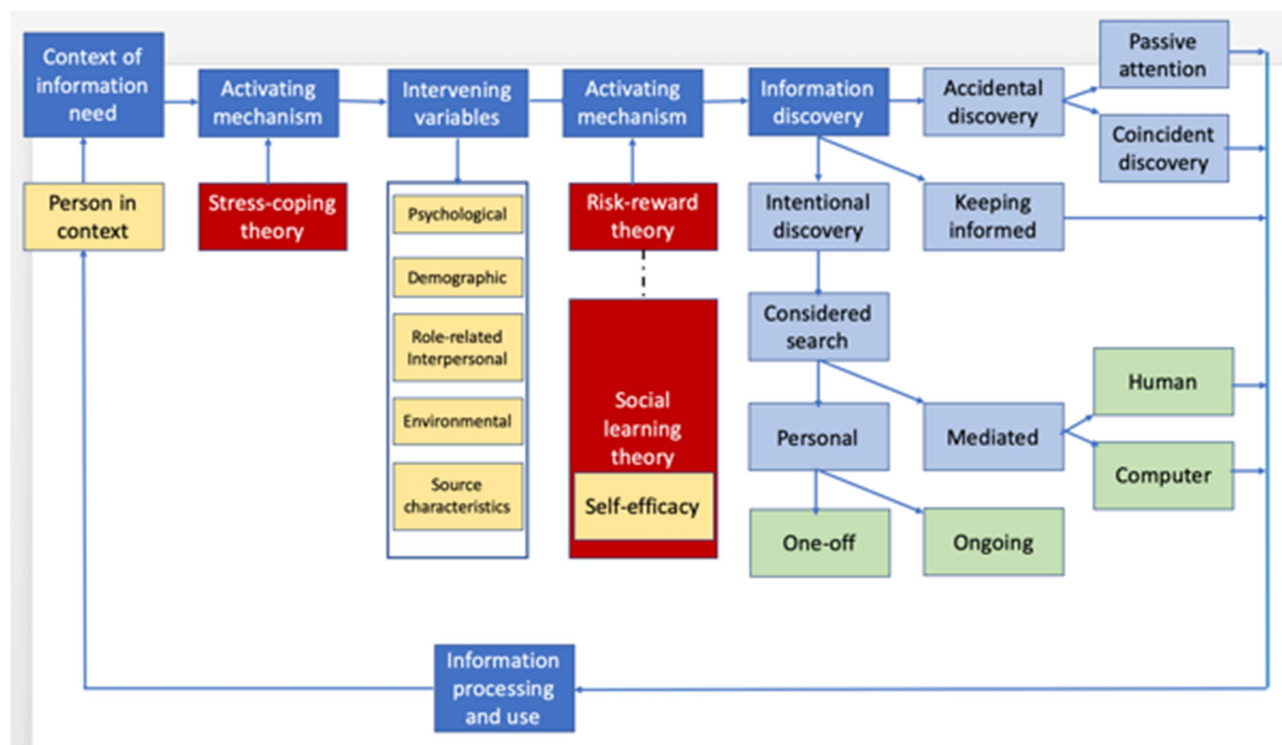

Figure 6. The expanded model.

In my earlier models I had left the variable information use undeveloped, on the grounds that we really know very little about how the brain processes information. However, I had previously done research on how information was used in a more practical sense, and so I have developed that area, so that it now looks like this: 


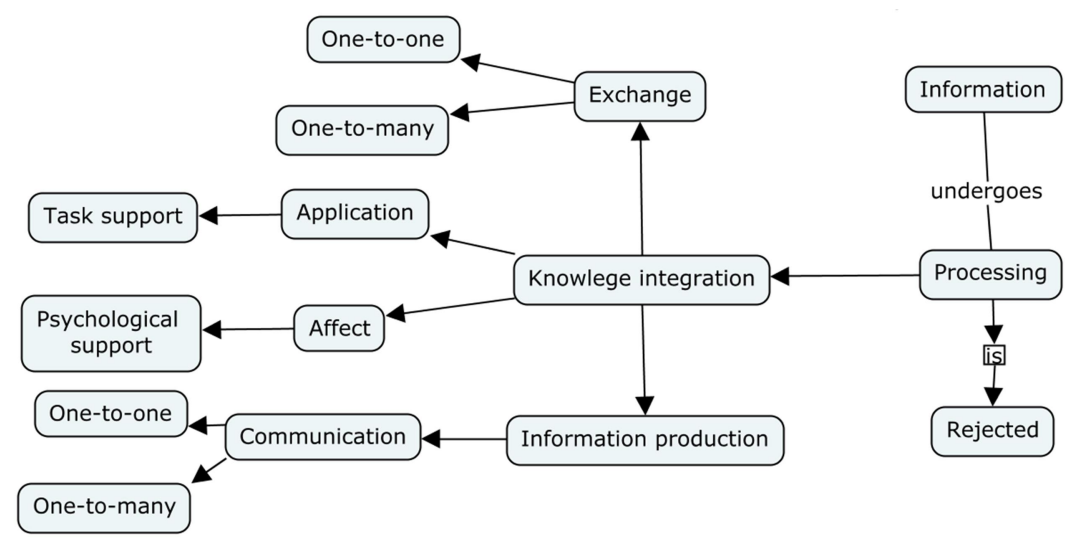

Figure 7. Modes of information use.

The processing activity is still a black box, but we can model what goes on when the information is integrated into our knowledge base (if it hasn't been rejected, for example, as fake news). Briefly, information may be applied in some way, for example to support a task, or to provide psychological support for ourselves - and if we exchange that information with others, they too may apply it in the same way. Exchange may be one-to-one, for example, with a friend or colleague, or one to many, for example, through a social media question and answer site. We may also use the information in preparing our own information outputs, communicating the information, again, one to one (for example, making a draft of a paper available to a colleague for comment), or one to many - presenting at a conference or publishing it in Information Research.

If I was to elaborate all of the boxes in the same way, I would probably need an A1-sized sheet of paper!

I do not imagine that this is the last word on the subject of models of information behaviour: even as I speak I am thinking of further expansions and revisions, so, in the making of models, there is no end!

I said at the beginning that this presentation arose out of the experience of writing a small book - I intend to make that book available by open access, possibly as a Kindle book, or as an EPUB. Of course I can also make it available as a pdf file. When it is available I'll announce it on various mailing lists, but if anyone wants a copy when it is ready just e-mail me atwilsontd@gmail.com

\section{REFERENCES}

AGARWAL, N.K. Towards a definition of serendipity in information behaviour. Information Research, 2015, vol. 20, $\mathrm{n}^{\circ}$ 3, paper 675. Retrieved from http://InformationR.net/ir/20-3/pape675.html (Archived by WebCite ${ }^{\circledR}$ at http://www.webcitation.org/6bIKHqubY)

ERDELEZ, S. Towards understanding information encountering on the Web. Proceedings of the Annual Meeting of the American Society for Information Science, 2000, vol. 47, p. 363-371.

WILSON, T.D. Models in information behaviour research. Journal of Documentation, 1999, vol. 55, nº 3, p. $249-270$ 